ASCLEPIO. Revista de Historia de la Medicina y de la Ciencia

66 (2), julio-diciembre 2014, p052

ISSN-L:0210-4466

http://dx.doi.org/10.3989/asclepio.2014.16

DOSSIER: BIOPODER Y DETERMINISMOS EN SUDAMÉRICA DURANTE EL SIGLO XX / DOSSIER: BIOPOWER AND DETERMINISM IN SOUTH AMERICA DURING THE TWENTIETH CENTURY

\title{
LA PERICIA MÉDICO LEGAL COMO FORMA DE PRODUCIR LA VERDAD Y SUS ADVERSARIOS EN LOS TRIBUNALES BRASILEÑOS DE ENTREGUERRAS
}

\author{
Luis Ferla \\ Universidade Federal de São Paulo, UNIFESP, Brasil \\ ferla@unifesp.br
}

Recibido: 1 agosto 2013; Aceptado: 14 abril 2014.

Cómo citar este artículo/Citation: Ferla, Luis (2014), "La pericia médico legal como forma de producir la verdad y sus adversarios en los tribunales brasileños de entreguerras", Asclepio, 66 (2): p052. doi: http://dx.doi.org/10.3989/asclepio.2014.16

\begin{abstract}
RESUMEN: La pericia médico legal confería impacto social a las tesis de la criminología positivista de orientación biodeterminista que ejerció gran influencia en el Brasil de entreguerras. Esa pericia transformaba los conocimientos especializados, o sea, los saberes científicos, en documentos aceptables y eficientes, inteligibles y utilizables. Disciplinaba las relaciones entre derecho y medicina y acababa viabilizando el poder de juzgar. Pero en ese recorrido debía afirmarse contras otras tradiciones y saberes. Sus principales "adversarios» eran: el conocimiento policial producido por constreñimiento del sospechoso del crimen, principalmente a través de tortura; las decisiones tomadas por el tribunal del jurado y la producción de pruebas a partir de las declaraciones de los testigos; y el saber del propio individuo delincuente. Todas estas otras formas de "producir la verdad» tenían en común el hecho de originarse en el mundo indocto, extra científico, lo que acabó constituyendo el principal argumento de los médicos legistas contra ellas. Las reflexiones a continuación se ocupan de las disputas por las prerrogativas en producir la verdad en los espacios institucionales dedicados a combatir el acto antisocial y tratan de demostrar las estrategias del discurso médico-científico para imponerse a las formas legas que con él convivían en esos ambientes.
\end{abstract}

PALABRAS CLAVE: Determinismo Biológico; Historia de la Medicina Legal; Antropología Criminal; Ciencia y Poder; Derecho y Ciencia.

\section{THE MEDICO-LEGAL EXAMINATION AS A MEANS OF PRODUCING TRUTH AND ITS OPPONENTS IN BRAZILIAN COURTROOMS DURING THE INTERWAR PERIOD}

\begin{abstract}
The medico-legal examination ensured the existence and the social impact of the biological positivist approaches to criminology that gained influence in Brazil during the interwar period. This examination turned scientific knowledge into accepted and acceptable documents that were also intelligible and useful. Examinations were social currencies used to facilitate the relationship between the power and knowledge of legal medicine and criminology. They disciplined the relationship between law and medicine and made feasible the power of judging. However, along the way they had to assert themselves against other traditions and knowledge. Their main "opponents» were the information obtained by the police from an offense or crime suspect through coercion, especially by means of torture; the decisions made by the jury and the evidence obtained from witnesses; and the delinquent's knowledge. What all these forms of «truth production» had in common was their non-expert origin, which became the main argument of forensic medical examiners against them.

The aim of this article is to discuss the dispute over the prerogatives to produce the truth in institutional spaces that dealt with combating antisocial acts, and to point out the medico-scientific strategies used to prevail over the lay forms present in that shared environment.
\end{abstract}

KEY WORDS: Biological Determinism; Legal Medicine History; Criminal Anthropology; Science and Power; Law and Science.

Copyright: () 2014 CSIC. Este es un artículo de acceso abierto distribuido bajo los términos de la licencia Creative Commons Attribution-Non Commercial (by-nc) Spain 3.0. 


\section{INTRODUCCIÓN}

Las reflexiones a continuación se ocupan de las disputas por las prerrogativas en producir la verdad en los espacios institucionales dedicados a combatir el acto antisocial y tratarán de demostrar las estrategias del discurso médico-científico para imponerse a las formas legas que con él convivían en esos ambientes. La pericia médico legal garantizaba la existencia y confería impacto social a las tesis de la criminología positivista de orientación biodeterminista que ejerció gran influencia en el Brasil de entreguerras. Esa pericia transformaba los conocimientos específicos y especializados, o sea, los saberes científicos, en documentos aceptables y eficientes, inteligibles y utilizables. Las pericias y los laudos eran las monedas sociales que lubricaban las relaciones de poder-saber de la medicina legal y de la criminología. Circulaban por todo el aparato represivo del Estado: en los tribunales, en las comisarías, en las cárceles, en los manicomios y en las correccionales. En esos ambientes adquirían poder de "vida y muerte». Disciplinaban las relaciones entre derecho y medicina y acababan viabilizando el poder de juzgar (Foucault, 2001, p. 8 y p. 153).

Pero iban aún más lejos al medir cuerpos y comportamientos en los más diversos espacios sociales, como escuelas y colas de empleo. Como veremos, cuando cuerpos y comportamientos no se medían, siempre había alguien exigiendo que se lo hiciera. En todos esos ambientes, la pericia médico legal fundamentaba decisiones acerca de la vida de los examinados al mismo tiempo en que pretendía mejorar el conocimiento científico. A su vez, la capilaridad social que alcanzó y la fluidez con que circuló atestiguaban su legitimidad científica.

La pericia no agotaba la comprensión de los mecanismos de poder, influencia y control social ejercidos por medio de la medicina legal en ese período. Sea en la pretensión inmersa en el discurso, sea en la realidad concreta, la medicina legal no tenía la intención de limitarse a su imprescindible función social de firmar en el renglón final de laudos y pericias. Como ejemplo se puede citar aquí su autoridad en las discusiones de las reformas legislativas, en especial las que se ocupaban de la reorganización del Código Penal brasileño, o el papel decisivo que cumplió en la creación de instituciones criminales y disciplinares, como el Instituto de Investigaciones Juveniles y el Manicomio Judicial de São Paulo. Pero no cabe duda de que la pericia era la pieza central en las prácticas sociales cotidianas de la medicina legal.

\section{LA AFIRMACIÓN DE LA PERICIA MÉDICO LEGAL EN EL AMBIENTE JURÍDICO}

A lo largo del siglo XIX, la pericia médico legal fue ocupando espacios dentro de los tribunales. Inicial- mente su papel se limitaba a definir si el agente del crimen se encontraba "en estado de demencia» en el momento en que lo cometió. Así lo prescribía el Código Penal francés de 1810 (Foucault, 2001, p. 39). El Código brasileño de 1830, en su artículo décimo, reproducía el mismo principio, que no consideraba delincuentes a los «locos de cualquier género, salvo que tuvieran intervalos de lucidez y cometieran el crimen en uno de ellos» (Peres, 2002, p. 337).

Eran formulaciones que acabaron identificándose con los preceptos de la Escuela Clásica de derecho penal al concebir el crimen como acto de la voluntad lúcida y, por lo tanto, consecuencia del ejercicio del libre arbitrio. Naturalmente, la locura era un estorbo para los defensores de esos preceptos, pues no permitía conciliar la "privación de sentidos» con la responsabilidad moral (Peres, 2002, p. 337). Pero justamente por eso, las leyes penales trataron de expulsar del campo jurídico la figura del loco. El instrumento para viabilizar esa «depuración» era la pericia médico legal. Como explica Foucault, la pericia debería permitir

establecer la demarcación: una demarcación dicotómica entre enfermedad y responsabilidad, entre causalidad patológica y libertad del sujeto jurídico, entre terapéutica y castigo, entre medicina y penalidad, entre hospital y prisión. Es necesario optar, porque la locura borra el crimen y, a la inversa, el crimen no puede ser, en sí mismo, un acto que se arraiga en la locura. Principio de la puerta giratoria: cuando lo patológico entra en escena, la criminalidad, de acuerdo con la ley, debe desaparecer. La institución médica, en caso de locura, debe tomar el lugar de la institución judicial (Foucault, 2001, pp. 39-40) ${ }^{1}$.

Sin embargo, el autor identifica, todavía en las primeras décadas del siglo XIX, el comienzo de la lenta construcción de esa «especie de continuum médico judicial, cuyos efectos e institucionalización consumada vemos en la pericia médico legal». Inicialmente, son los jurados los que comienzan a establecer el parentesco entre crimen y locura. En 1832, el reconocimiento legal de las llamadas «circunstancias atenuantes» permitiría que la «calificación, la apreciación, el diagnóstico del propio delincuente» fueran considerados en la elaboración de la sentencia. A partir de ese momento, la intervención médica en el ambiente jurídico sería cada vez más necesaria. Los conceptos de perversión y de peligro pasarían a orientar cada vez más las pericias médico legales y, por medio de ellas, los juicios penales. La idea de anormalidad substituía la idea de locura (Foucault, 2001, p. 40 y 43).

Según Fernando Salla, el primer laudo médico legal de la historia del encarcelamiento en São Paulo apareció posiblemente en septiembre de 1876 . El director de la Correccional había solicitado la transferencia de dos presos para el Hospital de Alienados, debido a la perturbación que causaban. El juez de primera 
instancia e instrucción nombró dos médicos para que elaboraran un dictamen sobre la condición mental de los presos. De acuerdo con Salla, "el informe carece de consideraciones propiamente médicas, pero es representativo de la reverencia, que ya comenzaba a esbozarse, del poder judicial con relación al saber especializado, en particular de la medicina, para pautar sus decisiones». No obstante, el autor aclara que esa iniciativa solo se generalizaría en las décadas siguientes (Salla, 1999, p. 101 y p. 129).

Sin embargo, es curioso observar que el crecimiento de la influencia de la criminología positivista, paradojalmente, no pasaba siempre por la imprescindibilidad del médico en el ambiente jurídico penal. En las últimas décadas del siglo XIX, esa corriente se expresaba principalmente a través de las ideas de Lombroso, cuyo carácter rudimentario facilitaba su utilización por agentes que poco o nada sabían de medicina. Ese es uno de los motivos de su difusión rápida y generalizada. Los estigmas físicos del delincuente nato se identificaban fácilmente en el sospechoso. Por esa razón, un comisario de la policía podía considerarse capacitado para examinar un delincuente y elaborar un dictamen sin la presencia de un médico. Así lo hizo, por ejemplo, el comisario de Brás, un barrio obrero de São Paulo, con el autor de un homicidio ocurrido en 1906:

Observé los principales rasgos fisionómicos del acusado, propios de un delincuente, de acuerdo con lo que enseñan los criminalistas. Advertí la prominencia de los arcos superciliares, la nariz alta y aquilina, las narinas anchas; el volumen exagerado de las mandíbulas; la separación de las orejas con la adherencia de los lóbulos; la boca contraída, amenazadora; la desproporción entre el desarrollo de la cara y el cráneo. Tuve la nítida impresión de que el hombre que tenía delante era feroz y peligroso. Encontré en él la mirada de la cual hablan Lombroso, Casper, Amadei y tantos otros (Fausto, 1984, p. 100).

La imposición de la legitimidad de saberes especializados de la medicina para garantizar la cientificidad de estos dictámenes ocurrirá en las décadas siguientes. Boris Fausto ubica el comienzo de ese proceso a mediados de los años 10, cuando textos burdos, como el que acabamos de reproducir, tuvieron que convivir con los dictámenes médicos más eruditos que comenzaban a ser emitidos en los procesos. Franco da Rocha firmó el laudo de 1916 en el que registraba la pericia realizada en un homicida internado en el Hospital de Juquery. El diagnóstico indicaba que el examinado era un «degenerado hereditario que sufre de una psicosis sistematizada interpretativa, cuyo delirio tiene como contenido los celos. Y, además, presenta episodios de depresión química ansiosa». Diez años y un abismo metodológico separaban este informe del dictamen emitido por el comisario de Brás. Además de utilizar principalmente conocimientos de psiquiatría (aunque haciendo uso aún de la antropometría), el informe de Franco da Rocha posee una sofisticación científica mucho mayor. Los indicios de anormalidad no podían ya ser identificados por la mirada de un indocto. Por ese motivo, y tal vez por encontrarse aún en un momento de transición rumbo a la consolidación del poder médico en el campo jurídico, Rocha parecía presionado a justificar sus conclusiones: "Convencer a los legos de que nuestro paciente es loco, como bien sabemos, es una tarea muy ardua» (Fausto, 1984, p. 100 y pp. 269-270).

A lo largo del período en estudio, ese convencer a los indoctos haría que se fueran dejando de lado cada vez más los argumentos basados en un posible universo de intelección común en pro del simple reconocimiento de la autoridad del médico y de la institución responsable por el laudo. En otras palabras, el laudo se transformaría en un documento cada vez más científico y objeto de la prerrogativa exclusiva de los médicos, más específicamente, de los médicos legistas. Dos procesos simultáneos y complementarios condicionaron esa transformación. Por un lado, la defensa de las prerrogativas profesionales de la categoría, incluso como parte de la propia lucha más general de los médicos contra la "charlatanería» y el libre ejercicio profesional, que fue muy intensa en las primeras décadas del siglo² ${ }^{2}$ Al optimizar la organización de esos intereses corporativos, la creación de la Sociedade de Medicina Legal e Criminologia de São Paulo, en 1921, contribuyó de forma decisiva al afianzamiento de los médicos legistas.

\section{LA PERICIA MÉDICO LEGAL EN CUANTO DISCURSO COMPETENTE}

En ese recorrido, la pericia médico legal fue constituyéndose en instrumento de ejercicio del poder. En cuanto documento escrito, legitimado por la ciencia y manipulado por jueces, policías y burócratas, ayudó a reescribir muchos destinos humanos. Al hacerlo a través de conocimientos científicos, la pericia nos coloca nuevamente en terreno foucaultiano, lo que nos permite retomar con pertinencia el concepto de saber-poder del pensador francés. No obstante, para imponerse, la pericia médico legal tuvo que disputar espacios con otras formas del saber y del conocimiento que también actuaban en el universo del crimen y de su represión. La falta de homogeneidad teórica para la elaboración de las pericias y los conflictos internos que existían entre las especialidades médicas involucradas ${ }^{3}$ exacerbaban aún más el conflicto externo con las otras formas de saber. Sus principales "adversarios» eran: el conocimiento policial producido por presión ejercida sobre el sospechoso de delito o crimen, fundamentalmente por medio de tortura; las decisiones tomadas por el tribunal del jurado y la producción de pruebas a partir de declaraciones de 
testigos; y el saber del propio individuo delincuente. Lo que todas estas otras formas de "producir» la verdad tenían en común era el hecho de originarse en el mundo indocto, extra científico, lo que acabó siendo el principal argumento de los médicos legistas contra ellas ${ }^{4}$. El reconocimiento del poder de la medicina legal descansaba en la descalificación de estos competidores. Marilena Chauí trata de esa estrategia en su texto sobre el discurso competente:

El discurso competente se instala y se conserva gracias a una regla que podría ser resumida así: no es cualquiera que puede decir cualquier cosa a cualquier otro en cualquier ocasión y en cualquier lugar. Con esta regla, él produce su otra cara: los incompetentes sociales (Chauí, 1982, p. 2).

La imposición y el reconocimiento sociales de la pericia médico legal pueden entenderse desde esa perspectiva. Más específicamente, dentro del recorte espacial y temporal que aquí se propone, el Brasil de entreguerras, eso ocurre cuando se articulan las teorías científicas vinculadas a la criminología positivista con el universo del derecho penal y del aparato represivo estatal. En esos espacios tuvo que convivir, casi siempre de forma conflictiva, con las otras formas de saber a las que aludimos anteriormente. Abordaremos ahora las relaciones entre ese saber científico puesto en funcionamiento por la pericia médico legal y los adversarios que debía descalificar y substituir. Comencemos por lo que es más cercano al médico legista: el saber del propio individuo que él examinaba.

\section{LA SUPRESIÓN DEL YO}

"Contra estas verdades científicas, la voz del reo nada puede» (Fausto, 1984, p. 264).

Erving Goffman, al estudiar las instituciones totales, analiza el proceso de "despojo del yo" a que es sometido el interno. Para el autor, todo comienza con la creación de una barrera entre la institución y el mundo exterior, que reduce el acceso a las referencias cotidianas que hasta entonces definían al yo. Es lo que el autor llama «despojo del rol». En ese sentido, una estrategia decisiva son los «procesos de admisión» por medio de los cuales el nuevo interno es desvestido, fotografiado, separado de sus bienes personales, catalogado, numerado, examinado, en fin, sometido a una serie de procedimientos normalizados que le confieren al recién llegado su nuevo papel de interno, que es desde ese momento el único que le corresponde legítimamente y el que se sobrepone a todos los otros con los que solía identificarse (Goffman, 1974, pp. 24-25).

La pericia médico legal hace parte de esa estrategia que actúa durante todo el período de internación. En cuanto procedimiento médico y también como docu- mento escrito, desconstruye y reconstruye el cuerpo y la mente del delincuente y los traduce en un lenguaje científico. La documentación que produce el ritual médico, el laudo en lo individual y el prontuario en lo colectivo, se destinan a "substituir» un individuo por otro. Foucault le da el nombre de «doblete» (Foucault, 2001, pp. 19-26), tomando prestado el término del teatro, donde su sentido es la substitución de actores en una obra. El individuo que la justicia juzgará o que la cárcel manipulará no será más aquel que cometió el crimen, sino el que fue traducido al lenguaje médico legal y presentado al tribunal o al director de la cárcel a través del respectivo laudo. La única expectativa de esas "autoridades responsables» es que el individuo que se presenta a juicio haya sido construido con un método científico riguroso y objetivo.

A lo largo de la vida del individuo secuestrado o perseguido por el aparato represivo del Estado, el conjunto de documentos generado a su respecto el prontuario - acompaña gran parte de su destino. Muchas de las decisiones que se tomarán sobre él buscarán fundamentarse en el contenido del prontuario. Es lo que Foucault denomina "poder de escritura» (Foucault, 1999, p. 157). Goffman, por su parte, alude a un mecanismo tautológico que da sustentación al prontuario y le confiere sentido: se registran selectivamente inconveniencias del comportamiento del individuo internado que, a su vez, se utilizan para justificar las razones de su internación (Goffman, 1974, p. 132). Si hubo necesidad de internación, ya queda plasmada la anormalidad del internado, que puede comprobarse en el registro de su comportamiento cotidiano en la institución. Hay, por lo tanto, una tendencia institucional para que el prontuario registre informaciones desvalorizadoras que refuercen la anormalidad del "paciente», de cualquier manera muy diferentes de las que él vincularía a sí mismo (lo que el autor identifica en hospitales psiquiátricos se aplica perfectamente a los presidios, como él mismo deja claro al definir el objeto de su libro, las instituciones totales):

Por regla general, los hospitales psiquiátricos divulgan, pues, sistemáticamente, el tipo de información sobre cada interno que este puede tener mayor interés en ocultar. $Y$ emplea a diario tal información, más o menos pormenorizada, para desautorizar sus reclamaciones (Goffman, 1974, p. 137).

Podemos añadir aún que no solo las reclamaciones del paciente quedan desautorizadas por el registro escrito, sino que también a partir de él serán evaluadas las solicitaciones concernientes a la alteración de su pena: pedidos de transferencia de sección o presidio, pedido para comenzar a trabajar o para cambiar de taller e, inclusive, para suspensión de penalidades, por ejemplo. En el caso de nuestra investigación, el beneficio más importante subsidiado por el prontuario era la libertad condicional, decidida por el Consejo 
Penitenciario a partir de la recomendación del Director del Presidio que, a su vez, se fundamentaba en el prontuario. Flamínio Fávero, con la autoridad de quien era presidente del Consejo y había sido Director de la Penitenciaria de São Paulo, explicaba el papel del Instituto de Biotipología Criminal de esa institución y de sus pericias en ese engranaje:

Tales elementos [que sustentan las decisiones del Consejo Penitenciario] están representados, en su mayoría, por el estudio que el Instituto de Biotipología Criminal realiza sobre el presidiario. (...) Puedo afirmar que ese Instituto es la columna vertebral del Departamento de Presidios, sin cuya actuación sería ya imposible ejecutar correctamente las sentencias de tipo progresivo que el Código exige y, también, el perfecto trabajo del Consejo Penitenciario (Fávero, 1947, p. 274-275)

Es interesante acompañar la migración del parecer del Instituto de Biotipología Criminal al Consejo Penitenciario, pasando por el Director del Presidio. En un laudo de un interno que solicitaba conmutación de la pena, elaborado por el Instituto, las conclusiones indicaban que

su vida, de acuerdo con su respectivo historial, tanto individual como familiar y social, fue siempre irregular y desastrosa, revelando desproporción de las reacciones individuales frente a los estímulos ambientales, carácter inarmónico y descoordinado, que oscila entre las actitudes apáticas y las explosivas; revela acentuada intolerancia psicofísica y conducta típicamente antisocial, además de 'sufrir' a causa de su anormalidad, en un verdadero círculo vicioso sinérgico de dolor - sufre y hace sufrir. Con base en esas observaciones y en el estudio biotipológico analítico y sintético de su personalidad, afirmamos que se trata de una personalidad psicopática (limítrofe), que parece ser del tipo constitucionalmente perverso (Teles, 1947, p. 168).

Ya en el informe del Director de la Penitenciaria puede leerse:

Mi parecer es contrario a la concesión de la gracia solicitada. El peticionario es reincidente específico. Ya cumplió en vano pena en esta Penitenciaria. Esta vez, mal adaptado, recorrió varios talleres sin permanecer en ninguno. Como explica el Instituto de Biotipología, el pronóstico criminológico del recluso es negativo y su peligrosidad es elevada. (Queiroz Filho, 1947, p. 169).

Por último, el dictamen del Consejo Penitenciario cierra el caso de la siguiente manera:

El instituto de Biotipología, en parecer esclarecedor, muy bien elaborado, nos convenció de que el peticionario posee una personalidad psicopática. Por eso, aunque su pena haya sido ya casi totalmente cumplida, no es posible otorgarle libertad condicional (Fávero et al, 1947, p. 169-170).
Por otro lado, la sombra del prontuario podrá acompañar la vida del prontuariado más allá del período de «internación». En 1943, el Director General de la Secretaría de Seguridad Pública de São Paulo, Alfredo Issa Ássaly, escribió un parecer acerca de un pedido de "cancelación de prontuario». El solicitante, un obrero italiano residente en Santos, había cometido un hurto el 18 de octubre de 1934 y fue condenado a seis meses de prisión. Beneficiado por una remisión condicional de la pena, recobró la libertad el 27 de enero de 1935. El motivo de su solicitación era la dificultad de conseguir trabajo debido al registro del delito y de la pena en su certificado de antecedentes penales. El parecer fue favorable a la eliminación de esas informaciones del certificado; sin embargo, la solicitud de cancelación no fue aprobada. La justificación del hecho es importante para entender la amplitud del poder de la escritura. Para el evaluador, la cancelación no podría ser atendida, «(...) ya que el prontuario nace con la identificación del individuo, cuya vida acompaña, y subsiste incluso hasta después de su muerte, registrando sus datos técnicos, científicos y policiales, que son de interés para la sociedad (...)» (Ássaly, 1943, p. 512).

Por haber cometido un hurto a los 19 años de edad, el solicitante tenía que conformarse con la idea de que esa información estaría siempre a disposición en alguna carpeta de algún archivo de la estructura burocrática del Estado durante toda su vida y también después de su muerte. Su experiencia en vida hasta ese momento lo había motivado a moverse en los meandros de esa estructura escribiendo peticiones y aguardando dictámenes con el objetivo de anular los efectos perniciosos que resultaban del registro escrito de su pasado y dificultaban la obtención de un puesto de trabajo. Que su certificado quedara «limpio» fue sin duda una victoria importante para él. No obstante, el hecho de que su prontuario no desaparecería jamás representaba una amenaza permanente. Además, es posible conjeturar la existencia de muchos otros individuos, perjudicados por motivos análogos, que no tuvieron las condiciones, oportunidad y disposición del mencionado obrero para aventurarse en las infinitas instancias burocráticas del Estado en defensa de sus derechos. Así, la documentación que el aparato represivo producía acerca de un individuo podía interferir en su vida civil cotidiana por mucho tiempo, sobreponiéndose muchas veces a las informaciones que ese mismo individuo presentaba sobre sí mismo.

La descalificación de ese saber sobre la propia persona y su substitución por un saber de carácter científico y "oficial» ocurría en el interior del propio laudo médico legal. La voz del examinado no estaba completamente ausente de la pericia. Los registros de los interrogatorios de tipo psicológico, en su mayoría, transcribían las preguntas y las respuestas por exten- 
so. En algunos casos, constituían la parte principal de la pericia, que llevaba varios días y resultaba en informes de muchas páginas de extensión. Sin embargo, el laudo escrito poseía estratificación para facilitar su lectura y manejo por parte de los diversos agentes sociales involucrados en su utilización. Para las autoridades del universo judicial y del aparato administrativorepresivo del Estado, donde se encontraban los jueces de primera instancia e instrucción y los directores de presidios, era interesante, por ejemplo, el diagnóstico final en el que sus decisiones buscaban las justificaciones científicas. Pero antes de esas líneas finales y decisivas, el informe procedía a depuraciones periódicas de su contenido a través de ítems denominados «súmulas». Después de cada etapa de la pericia, incluidas las mediciones antropométricas, los tests psicológicos y los largos interrogatorios, aparecían las súmulas para traducir, resumir y concluir todo el conjunto de informaciones recientemente producidas. Esta forma de organizar el contenido del laudo facilitaba no solo la lectura por parte de los que estaban interesados en algo más que la conclusión final, sino también el trabajo de producción de diagnósticos por parte del equipo examinador. En realidad, el diagnóstico final correspondía a una información que, después de pasar por varias etapas intermedias, llegaba a su máximo estado de depuración. Poco a poco y a lo largo del informe, el lenguaje normalizado de la ciencia iba sustituyendo las informaciones desorganizadas y desarticuladas. De esa manera, también la voz del paciente sufría intervenciones y era transformada, diluida e interpretada por el examinador.

Un ejemplo de lo que acabamos de describir aparece en el informe de I. de la S., vulgarmente conocido como Pernambuco, que fue considerado inocente en un homicidio ocurrido en "obras adyacentes al nuevo viaducto do Chá» en la ciudad de São Paulo en mayo de 1938. El reo se acusaba de un asesinato que en realidad no había cometido, pues quedó comprobado que se trataba de una «muerte natural». La víctima era un sereno, cuyo cuerpo fue encontrado en «obras adyacentes al nuevo viaducto do Chá». Al comienzo parafraseado, después transcripto literalmente, Pernambuco explicó cómo lo llevaron preso y cómo acabó confesando un crimen que no había cometió:

El día que lo llevaron preso, a las 11 de la noche, en el Jardín América, estaba haciendo tiempo para dormir al lado de una pequeña construcción, 'creía que en ese lugar la policía no me encontraría - además tampoco había sereno. Pasaron dos sujetos que me dejaron una cosa - que después vendrían a recoger - y siguieron camino rápidamente - no corrieron. Después llegó el sereno: - Muchacho, ¿qué estás haciendo aquí? - Estoy haciendo tiempo para ir a dormir. - ¿Qué tienes ahí? - Unos muchachos me pidieron que lo cogiera. Entonces lo abrió y había una porción de cosas. El sereno saco el silbato y lo hizo sonar - llegó el coche: Es ese tipo. Y empezaron a pegarme; me dieron muchos golpes - ahí le pegué a uno - me dieron una trompada en la nariz - me rompieron los dientes. Les dije que no era ladrón, que no había robado esas cosas, que había cometido una falta, pero no era la de robar. Entonces describí el crimen. Ellos no me creyeron - porque estaba mareado. Estoy seguro que no me creyeron, porque yo estaba mareado. Recién aquí me tomaron en serio'.

'¿Por qué 'decidió' contarlo?'

'Porque tenía ganas de hablar y para que no me pegaran más - es una banda - si fuesen dos - en un rincón - yo aguantaba - no fue la cachiporra, no, si querían podían matarme que yo no hablaba, pero fue por voluntad propia, yo lo quería contar (Whitaker, 1943, p. 296 y pp. 300-301).

En el correspondiente resumen de este y otros interrogatorios, el fragmento relatado por Pernambuco se transformaba en algo que iba más allá de lo sutilmente diferente:

el 13 del mismo mes fue preso, sujetando un paquete, el individuo I. de la S. en las cercanías de determinada residencia situada en el barrio de Jardín América - que había sido asaltada - por policías que perseguían al autor del asalto. I., durante la lucha que sucedió a la voz de prisión, afirmó ser inocente del asalto, pero confesó ser culpable de un crimen de muerte, cuya víctima era C.A., el sereno antes mencionado (Whitaker, 1943, p. 307; bastardilla nuestra).

La paliza que le dieron a Pernambuco se transformaba en "lucha que sucedió a la voz de prisión». Desaparecieron en esa traducción tanto la violencia policial como la asociación que el examinado había establecido entre violencia y confesión. Más allá de que la falsa autoacusación hubiera sido motivada por una psicopatía, que la pericia acabaría diagnosticando, o por la truculencia de la Policía o, incluso, por ambas cosas a la vez, el hecho es que la versión de Pernambuco quedó tan diluida que se vuelve casi irreconocible y se pierde la posibilidad de establecer ilaciones con relación a la institución en que trabajaban los examinadores.

En ese mismo laudo encontramos otro ejemplo del celo institucional, tal vez inconsciente, de los médicos de la Policía. Varias veces, Pernambuco se queja de las condiciones de la cárcel y de su salud: "Sufro mucho. Mala comida, sabañones, dolor de muelas.», "Estoy harto de estar aislado en una celdita. Me han enterrado vivo», "Me tienen aislado. Pongan ahí un diputado y seguro se muere.» En el resumen, la "traducción» es: «En la pericia siguiente se mostró muy descontento con su situación de preso (...)» (Whitaker, 1943, pp. $323-325$ y p. 338; bastardilla nuestra $)^{5}$.

La voz del examinado acababa anulada por esos mecanismos. El discurso médico la atropellaba haciendo uso de su legitimidad y de la descalificación del saber 
sobre sí mismo que poseía el examinado. El laudo así producido era puesto en circulación en el aparato represivo, donde otros obstáculos para su plena y efectiva aplicación podrían surgir.

\section{EL CONSTREÑIMIENTO POLICIAL EN CUANTO MÉTODO PARA PRODUCIR LA VERDAD}

El celo institucional de los médicos de la policía no significaba subordinación al saber y a los métodos de los agentes policiales. Al oponer tratamiento a castigo y ciencia a violencia, la criminología médica frecuentemente se colocaba como alternativa a los métodos más truculentos y deshumanos de combate al crimen. No solo consideraba sus técnicas más coherentes con las conquistas civilizatorias iluministas, sino que también les atribuía mayor eficiencia en la defensa de la sociedad. Por esa razón, las diversas formas de constreñimiento policial en las investigaciones se consideraban supervivencias incómodas de una concepción de policía que los conocimientos científicos y los sentimientos humanitarios ya estaban en condiciones de superar. Los laudos médicos eran parte de esa estrategia. Entre sus conclusiones y las que se obtenían en interrogatorios policiales en condiciones sospechosas, las autoridades competentes no debían dudar. El informe médico legal debía gozar de estatuto de verdad. Desde una perspectiva más estratégica, se pensaba que su generalización acabaría transformando la violencia policial como forma de producir la verdad en algo sin sentido.

Hubo casos en los que la pericia se confrontó directamente con las conclusiones (y métodos) de la investigación policial. Un caso de 1936 en São Paulo nos suministra un buen ejemplo. M.Z., cocinero de 22 años, húngaro, fue preso acusado de haber dado muerte por estrangulamiento a su amante después de que ella admitiera no ser virgen cuando lo conoció. Sometido a varios interrogatorios, M.Z. acabó confesando la autoría del crimen (Whitaker, 1936, p. 187). Sin embargo, el Delegado de Seguridad Personal parecía desconfiar de la autenticidad de la confesión. En la introducción del laudo se explicaba la razón por la que el Laboratorio de Antropología Criminal había sido llamado para aclarar el caso:

Habiendo aquel [el reo] declarado también, posteriormente, repetidas veces, no ser culpado de nada y haber confesado un crimen que no cometiera por influencia del temor que sintió al confrontarse con los investigadores, la autoridad decidió proceder a un examen antropo-psiquiátrico del caso para elucidar las dudas presentes (Whitaker, 1936, p. 187).

El laudo, después de relatar las conclusiones de la investigación policial a partir de la "confesión» de M.Z., significativamente informaba que esta se había obtenido en "condiciones propias de los interrogatorios policiales». Al final, la conclusión de los examinadores presentaba una tentativa de afirmación de la pericia frente a los métodos «indoctos» de los policías:

Ante estos resultados, podemos afirmar que la confesión del paciente tiene escaso valor, por cuanto colocado en determinadas condiciones (al sufrir un interrogatorio policial, por ejemplo) puede llegar a perder el control sobre sí mismo y reaccionar de manera equivocada, incluso confesando lo que se le sugiere (Whitaker, 1936, pp. 189-199).

Pero los peritos médicos estaban en condiciones de demostrar la superioridad del laudo no solo de forma negativa, refutando la validez de la confesión. EI test de Jung-Bleuler habría atestado la sinceridad del examinado: «De este modo, podemos considerar sinceras sus declaraciones, cuando, sin constreñimiento, afirma no haber cometido el crimen» (Whitaker, 1936, p. 199). Por lo tanto, no solo la confesión resultó destituida de valor, sino que también la ciencia fue capaz de demostrar la inocencia del acusado.

Finalmente, se buscaba demostrar de esta forma que todo lo que podía obtenerse en las oscuras salas de interrogatorio de la policía también podía ser obtenido por los médicos en la claridad de sus laboratorios, que contaban además con la ventaja de mayor confiabilidad y del respaldo de un discurso humanitario.

Sin embargo, aunque la verdad producida en la Policía y concretizada en el laudo pericial fuera el resultado del trabajo de médicos y no de agentes policiales, en los tribunales interferían otras formas de conocimiento extra científico. Era el caso, por ejemplo, de los jurados populares.

\section{EL JURADO POPULAR Y EL «REINADO DE LA IGNORANCIA»}

El juez Virgílio de Sá Pereira fue uno de los autores de los proyectos de Código Penal Brasileño que subsidiaron los trabajos de la comisión responsable por el texto final promulgado en 1940. En 1929, Sá Pereira dio una conferencia para abogados acerca de su proyecto. Para introducir el tema del jurado popular, el orador relató un "episodio cómico, pero instructivo» ocurrido en Araruana, una pequeña ciudad cerca de Río de Janeiro. Macedo Soares se había desplazado hasta allí para abrir una sesión del jurado. Los jurados, «en su mayoría hacendados y agricultores, llegaron como para una fiesta, engalanados con sus mejores trajes y montados en sus mejores caballos» (Pereira, 1929, p. 61). Lo que allí sucedió, desde la perspectiva del ilustre juez, era un buen ejemplo, aunque caricaturesco, del lugar ocupado por el tribunal del jurado en el sistema penal brasileño:

Había un solo proceso para ser juzgado, el de un reo que había causado heridas graves y que alegaba legítima defensa. A las tres de la tarde el jurado se retiró a 
la sala secreta y el juez ya se deleitaba con la posibilidad de volver a Cabo Frío ese mismo día. Van pasando las horas. El juez se inquieta. Piensa en mandar a un oficial de justicia o a un escribano para averiguar la razón de la demora, pero se abstiene delante del principio legal de incomunicabilidad. Lo único que puede hacer es esperar. Espera. Oscurece, se hace de noche. Finalmente, el juez pierde la paciencia, se levanta, va hasta la puerta de la sala secreta y escucha. Silencio. Había a mano una escalera y la apoya contra la pared. Sube los primeros escalones y acecha por el montante de vidrio. La sala está vacía. Los valientes jurados, ante la dificultad de responder sobre la cuestión de legítima defensa después de mucha reflexión, habían salido por la ventana, montado sus caballos y galopado de vuelta a sus chácaras y haciendas. En aquel entonces, señores, ellos tomaban su cabalgadura y huían para no responder las cuestiones de legítima defensa; hoy, para no responder a asuntos vinculados a la libre determinación de la voluntad, subirían a su automóvil (Pereira, 1929, p. 61).

En este fragmento, Sá Pereira sintetizaba las críticas a la institución del jurado popular que por aquel entonces movilizaban a buena parte de la intelectualidad brasileña. Por un lado, se denunciaba la deformación en su composición. Ya desde el siglo anterior había una percepción generalizada de que el jurado excluía a las clases populares, lo que transformaba su epíteto en algo sin sentido (Fausto, 1984, p. 229). En Araruama, los jurados eran los hacendados de la región. Esta crítica, más que pedir justicia social, llamaba la atención para una contradicción fundamental del así denominado «jurado popular», que comprometía su sentido filosófico. En segundo lugar, el jurado era considerado poco digno de confianza, ya que no asumía compromiso con la tarea para la que se lo había convocado ni con las instituciones jurídicas involucradas. No solo los «jurados-jinetes» abandonaron el foro de forma vergonzosa, sin cumplir con su deber, sino que llegaron como quien «llega a una fiesta, con su mejor ropa, montando sus mejores caballos».

Y, por último, el jurado no podía ser digno de crédito por la simple razón de que no poseía la capacitación técnica necesaria para tomar las decisiones solicitadas. Sá Pereira, en calidad de redactor de un proyecto de Código Penal, estaba siempre lidiando con temas delicados de la criminología que alimentaban acalorados debates entre clásicos y positivistas. Para tratar la cuestión de fondo de ese debate, la que oponía libre arbitrio y determinismo en la etiología del crimen, el jurisconsulto se veía obligado a moverse en campo minado y extremadamente intrincado para articular teorías sofisticadas de "sabios consagrados» de ambos lados. ¿Cómo podían los hacendados de Aruarama decidir cuestiones tan complicadas? ¿Y cómo iban a decidir el resto sin haber resuelto primero ese problema? Además, un juicio, desde la perspectiva de esos críticos, estaba totalmente estructurado en tor- no a cuestiones técnicas de medicina y derecho, áreas que les eran invariablemente extrañas a los jurados.

Por eso, el jurado se presentaba como un personaje indeseable en el ambiente jurídico, un «elemento opaco» en su lógica de funcionamiento (Foucault, 2001, p. 49). La oposición más feroz a su existencia siempre había venido de la Escuela Positiva, comenzando por su propio fundador. Lombroso consideraba la institución una manifestación atávica de etapas anteriores del desarrollo de la humanidad. Su funcionamiento más imperfecto, por esa misma razón, ocurría en los países más atrasados, de «clima cálido»:

Un resto de esa justicia primitiva que el pueblo ejercía en un momento de furia y que reconocemos entre los animales puede encontrarse aún hoy en el jurado. Principalmente en los países cálidos, el mismo jurado que castiga a un ladrón, absuelve a un homicida. ¿No nos recuerda esto los primeros crepúsculos de las justicia? (Lombroso, 2001, p. 122).

Su origen podría localizarse en la época en que los deseos de los poderosos o la irracionalidad de las multitudes ocupaban el lugar de la justicia, condenando o perdonando según sus caprichos:

Recuerden que la justicia frecuentemente fue la emanación de un capricho del déspota o del sacerdote, o de la furia popular, y ustedes comprenderán esa práctica entre pueblos que aún no se libertaron del derecho de gracia - derecho absurdo - que resulta del atavismo, ustedes entenderán el porqué del jurado - esa institución tan opuesta al objetivo perseguido, tan incierta, tan fácil de corromper, pero que tiene el mismo origen que el derecho de gracia (Lombroso, 2001, p. 123).

Los seguidores de Lombroso insistían en criticar al jurado. El jurisconsulto italiano Rafaello Garofalo fue uno de sus mayores enemigos, considerándolo una verdadera "vergüenza de los tiempos modernos", que lanzaba la justicia en las «garras de individuos ignaros dominados por las pasiones y por los prejuicios populares» (Darmon, 1991, p. 144-145). Para Garofalo, además de carecer de formación técnica, los jurados frecuentemente se vendían o se amedrentaban (Peset y Peset, 1975, p. 73). La escuela francesa coincidía con la escuela italiana en ese aspecto. El profesor Alexandre Lacassagne, de la Escuela de Medicina Legal de Lyon, que se caracterizaba por su perspectiva sociológica de la criminología y, por tanto, opuesta a los positivistas italianos, compartía con estos la crítica al jurado popular. Para él, los hombres de ciencia llegaron tarde a las salas de los tribunales, pero no deberían abandonarlas nunca más. El químico y el médico legista serían antídotos providenciales contra la ignorancia de los jurados. El perito surgía como el «verdadero representante de la ciencia, imparcial e infalible» (citado por Darmon, 1991, p. 157). Gabriel Tarde, juez de instrucción y filósofo de derecho penal de enorme 
influencia en la criminología francesa, defendía la sustitución del jurado por una «magistratura científicamente entrenada» (Harris, 1993, p.150). Ruth Harris demuestra cómo la oposición al jurado popular en Francia logró debilitarlo a lo largo del siglo XIX ${ }^{6}$. Esa confluencia entre franceses e italianos permitió la aprobación de una moción para suprimir el jurado en el II Congreso Internacional de Antropología Criminal, que se realizó en París en 1889 (Foucault, 2001, p.49).

En Brasil, la llegada de la Escuela Positiva de derecho vino acompañada de la crítica al jurado. En las discusiones en torno a la Constitución de 1891, los positivistas ya defendían su extinción. Viveiros de Castro, uno de los primeros difusores de la nueva Escuela en el país, sostenía que la modernización bajo la égida de la ciencia que postulaban los positivistas conllevaba a la supresión del jurado. Para él no se podía continuar permitiendo que

individuos sin conocimientos técnicos sobre las leyes del proceso, de la teoría de las pruebas, de los factores que afectan la responsabilidad criminal juzguen asuntos que deberían ser tan solo de responsabilidad de peritos (Alvarez, 1996, p. 92).

En São Paulo, Cândido Mota compartía esa opinión y consideraba, incluso, que la existencia del jurado sería una de las principales causas de criminalidad. Marcos Alvarez, en su estudio sobre la influencia de la Escuela Positiva en el ambiente jurídico brasileño, considera que la campaña que los positivistas realizaron contra el jurado ayuda a explicar la tendencia de reducción de sus atribuciones a lo largo de la Primera República (Alvarez, 1996, p. 115 y p. 135). Es por ese camino que reencontramos a Sá Pereira en 1929 discursando para sus colegas jurisconsultos y abogados sobre los jurados «huidizos» de Aruarama.

Después de los años 1930 continuamos encontrando en el medio jurídico la misma hostilidad hacia el tribunal del jurado. El 30 de noviembre de 1932, Cesar Salgado daba una conferencia en la Sociedade de Medicina Legal e Criminologia de São Paulo. Salgado era promotor público y presidente de la Sección de Criminología de la entidad. En la conclusión de su presentación, intitulada "Nuevos rumbos de la criminología», el conferenciante trata de sintetizar lo que vislumbraba en el horizonte del combate al crimen:

El psicoanálisis en la ciencia jurídico penal. La endocrinología en la apreciación de los factores criminógenos. La falencia del jurado como organismo distribuidor de justicia y represor del delito y la necesidad de su supresión o reforma completa (Salgado, 1932, p. 69).

Para Salgado, en breve el tribunal sería demasiado pequeño como para albergar jurados y científicos. Con el inevitable fortalecimiento de estos últimos, los primeros se volverían cada vez más inútiles y dispensables.
Entre los médicos, de cierta forma con más pertinencia, también eran grandes el entusiasmo con la participación de la ciencia en el derecho penal y el consecuente malestar con el tribunal del jurado. Asimismo era constante la defensa de su extinción o de su «encogimiento». José de Moraes Mello, psiquiatra de la Penitenciaria de São Paulo, defendía, por ejemplo, la «tecnización» de la Justicia en toda su extensión:

(...) la ejecución de las medidas de defensa social exige, además de la estructura adecuada, personal idóneo y desde el juez - el jurado popular debería desaparecer - hasta el último empleado o auxiliar de las ejecuciones de las sentencias, todos precisan tener preparación técnica de acuerdo con las funciones y personalidad moral inatacable (Mello, 1928, p.32) 7 .

Sin embargo, las perspectivas acerca del tribunal del jurado no eran solo alimentadas por la creencia en las posibilidades de la ciencia en asuntos de criminología. El tema siempre tuvo un sesgo político muy fuerte. Su defensa invariablemente estaba asociada a posiciones más liberales e iluministas. De cierta forma, la valorización de las prerrogativas del jurado popular o, inversamente, su desvalorización pueden decirnos algo sobre el nivel de liberalismo político de determinada sociedad en determinada coyuntura. En Brasil, la institución surgió en junio de 1822, poco antes de la independencia política. Fue creada para juzgar tan solo los crímenes de prensa. Su reglamentación más extensiva se dio con el Código de Proceso Criminal de 1832. Desde entonces, se ampliaron o se limitaron sus atribuciones según prevalecieran en la política brasileña los conservadores o los liberales. La primera Constitución republicana, de 1891, mantuvo la institución, pero descentralizó su reglamentación, que quedó a cargo de los Estados (Fausto, 1984, p. 226-227).

No obstante, como ya indicó Marcos Alvarez, durante la Primera República prevaleció la reducción de las atribuciones del tribunal del jurado. En São Paulo, una ley de 1925 transfirió casi todos los crímenes al Juez de primera instancia e instrucción, y la apreciación de los jurados se limitaba a homicidios dolosos y tentativas de homicidio (Fausto, 1984, p.227). La dictadura de Vargas tampoco revirtió esas tendencias.

Al contrario, una ley restrictiva de 1938 motivó una crítica irónica que sugería la siguiente enmienda: «Extingue el Tribunal del Jurado, le conserva el nombre y se dictan otras disposiciones" (Lehmann, 1947, p.183). En el debilitamiento del tribunal del jurado confluyen el autoritarismo, el antiliberalismo político y las perspectivas de modernización del país bajo la égida de la ciencia. En 1945, con la redemocratización de la política, los jurados volvieron a ser valorizados. La Constitución de 1946, la más democrática que el país había conocido hasta entonces, transfirió el tema del jurado popular al capítulo referente 
a las garantías individuales (Lehman, 1947, p. 184). Sintomáticamente, los pareceres del Consejo Penitenciario pasaron a exaltar el tribunal del jurado y la democracia, enfatizando la relación entre ambos ${ }^{8}$. Y fueron aún más lejos al emitir pareceres que defendían la retroactividad de la nueva Constitución, con el objetivo de anular sentencias del «Egregio Tribunal de Apelación» en aquellos casos en que esa instancia había contrariado decisiones del tribunal del jurado. Las justificaciones que se daban para ese procedimiento eran un reflejo del momento político más que de tecnicidades jurídicas:

(...) no veo porqué J.G.M. deba ser perjudicado por una ley que aniquiló la soberanía del Jurado como reflejo del conocido miedo de los dictadores (...) Si el pavor de los usurpadores ahoga instituciones liberales y democráticas, no nos parece justo mantener el indeseado e indeseable régimen mediante obediencia pasiva a execrables leyes oriundas de un poder ilegítimo (Ferreira, 1947, p. 221).

Nada más distante de las elegías a la ciencia, a los peritos y a sus pareceres en contraposición a la «ignorancia» y a la falta de confiabilidad de los jurados. Sin duda, el discurso había cambiado, como también había cambiado el momento histórico. Pero a lo largo del período del que nos ocupamos, como vimos, era la ciencia que avanzaba y el jurado que retrocedía. Y junto con él, el testigo, igualmente acorralado por el discurso competente.

\section{EL TESTIGO Y EL TESTIMONIO BAJO SOSPECHA}

"El Papa (...) jugando al trompo en compañía de varios chavales en el Largo da Sé...»

Parece que el relato jocoso era una estrategia común entre los positivistas para descalificar las formas de producir verdad que la ciencia combatía dentro de los tribunales. El renombrado jurisconsulto Alcântara Machado hacía reír a sus alumnos de Medicina Legal del curso de Derecho:

Para demostrar el desprestigio del testimonio entre nosotros como en todos lados, más significativa que mil citas de autores antiguos y modernos es aquella boutade del viejo magistrado paulista que cierta vez se comprometía a justificar en juicio, con testigos contestes, que en la víspera el Papa había estado jugando al trompo en compañía de varios chavales en la plaza da Sé... (Machado, 1929, p. 48).

El discurso que desvalorizaba al testigo y el testimonio se apoyaba esencialmente en la misma oposición entre ciencia e ignorancia que pautaba las críticas al tribunal del jurado. Nuevamente, se trataba de avanzar en la aceptación de los criterios científicos para las decisiones judiciales, retirando del camino los «impresionismos», las "emotividades» y la ignorancia del «mundo indocto».
Pero aquí la estrategia poseía una diferencia fundamental. El adversario en ese caso no debía ser expulsado del tribunal, sino colocado bajo control. El testigo debía seguir siendo un personaje del enredo judicial - expulsarlo de la escena era impensable pero lo que no era más tolerable era mantenerlo en el papel protagónico que muchas veces asumía. Se condenaba la valorización exagerada de las declaraciones, que frecuentemente adquirían valor absoluto sin ser cotejadas con otras pruebas. Significativamente, se señalaba como principal responsable de esa estimación excesiva al tribunal del jurado, que consideraba el testimonio como "la prueba por excelencia» (Rodrigues, 1922, p. 108). Desde la perspectiva de la medicina legal, la articulación testigo-jurado popular era vista como una especie de alianza tácita entre legos contra el reino de la ciencia dentro del tribunal.

Ese fue un problema que ocupó varias sesiones de la Sociedade de Medicina Legal e Criminologia de São Paulo. En realidad, era uno de sus temas prioritarios, como se observa en sus informes de actividades, en los que ese asunto aparece recurrentemente desde los tiempos de su fundación (Fávero, 1936, p. 150). Para el siempre citado Oscar Freire, el testimonio no era «el mejor medio para conocer 'el alma del delincuente' en lo que se refiere al interés que ese conocimiento puede tener para el derecho penal. Más importante es el examen psíquico realizado conscientemente por un observador facultado que dispone de recursos apropiados» (Rodrigues, 1922, p. 117).

Las ponderaciones contra el "fetiche» de la declaración (Rodrigues, 1922, p. 107) partían casi siempre de la llamada "psicología del testimonio», una ciencia que había surgido a comienzos del siglo XX y que ganaba espacio y reconocimiento. Esta ciencia se originaba en los estudios de Alfred Binet ${ }^{9}$ sobre la sugestionabilidad (Katzenstein, 1940, p. 202). Volviendo a la clase de Alcântara Machado, encontraremos al profesor explicando a sus alumnos que, en 1900, el psicólogo había realizado investigaciones para comprobar cómo sería

fácil, mediante un interrogatorio conducido a la manera de los interrogatorios e inquisiciones policiales, falsear los recuerdos de cualquier persona en relación con los hechos que presenció y llevarla a afirmar algo sinceramente divergente de la realidad (Machado, 1929, p. 49)

Por lo tanto, en lo que se refiere a testimonios, la propuesta de los positivistas era someterlos a evaluación, «medición» y calificación por medio de metodologías científicas, principalmente del «examen del testigo». De esa manera, el examen pericial debería predominar sobre la declaración, asumiendo su prevalencia en la jerarquía de las pruebas judiciales por medio, justamente, de la ampliación de su aplicación: no solo deberían examinarse los delincuentes (y 
eventualmente sus víctimas) sino también los propios testigos. Ellos se transformarían así en objetos de la ciencia y por ella serían valorados.

Pierre Darmon describe el caso de la «Ogra de la Goutte-d'Or» como la primera gran victoria de la medicina legal sobre el testimonio y el sentido común. En la primera década del siglo XX en Paris, una mujer bretona de unos 30 años había sido acusada de la muerte por estrangulamiento de varios niños, entre ellos algunos bebés. La acusada vivía en el miserable, insalubre y populoso barrio de Goutte-d'Or, que originó su epíteto. El juicio movilizó intensamente a la opinión pública y a la prensa de la ciudad. Léon Thoinot, discípulo de Tardieu y considerado el sucesor del gran Brouardel en la cátedra de medicina legal de la Facultad de París, procedió a la autopsia de los pequeños cadáveres y emitió un laudo que descartaba el estrangulamiento, lo que posibilitaba la absolución de la acusada. El laudo de Thoinot desautorizó así varias declaraciones que la incriminaban, y su claridad meridiana hizo que hasta el promotor público se curvara y retirara la acusación. La medicina legal exultó con la victoria y la multiplicó en conferencias y artículos sobre el caso. Uno de ellos, sintomáticamente intitulado "Historia de un duelo entre dos mentalidades", publicado en los Archives d'Anthropologie Criminelle en 1906, interpretaba el evento como un triunfo de los médicos "orientados hacia el futuro» sobre los magistrados "anclados al pasado». Sin embargo el caso sufre un giro. La acusada, después de su liberación, vuelve a asesinar y es detenida en flagrancia. Además, los avances posteriores de los conocimientos científicos de la medicina legal comprobaron el error de Thoinot. El balance final de esa historia hizo que se relativizara el laudo pericial y que la declaración de testigos continuara teniendo espacio en los juicios (Darmon, 1991, p. 251-267).

En Brasil, según Ferreira Antunes, los primeros casos de intento pericial de descalificar testimonios presentados en juicio ocurrieron a fines del siglo XIX. Se iniciaba en ese momento la pericia de sanidad mental de los testigos, lo que para el autor caracterizaba la apertura de un nuevo campo para la medicina legal. Ya en 1907, Juliano Moreira proponía extender la pericia a testigos de edad avanzada (Antunes, 1999, p. 94-95).

Desde entonces, la tendencia sería tratar de borrar la frontera entre el testigo "anormal», digno de desconfianza por su propia condición, y el testigo «normal» que sería, a ojos de los indoctos, absolutamente confiable. El ataque a los testimonios y a los testigos buscaba justamente hacer ver que todas las declaraciones serían pasibles de alguna deformación, por eso la ciencia debería intervenir para calificarlas. El papel central para eso estaba reservado al psicólogo. Betti Katzenstein, psicóloga del Laboratorio de Psicología de la Universidade de São Paulo, lo explicaba en una conferencia en la Sociedade de Medicina Legal e Criminologia. Es difícil imaginar la viabilidad de la generalización de su propuesta:

Tratándose del estudio de la veracidad de determinado testigo, sea con referencia a un individuo o a un grupo de individuos, el psicólogo precisa poner en acción todos los métodos que pueden ayudarlo a estudiar el caso; precisa hacer observaciones en los ambientes donde se desarrolla la vida del individuo; aplicar pruebas y tests si necesario; conversar con la persona, leer los autos y, si se trata de niños, hablar con los padres y profesores, auxiliares valiosos para el trabajo del psicólogo, - entre otras cosas (Katzenstein, 1940 , p. 204) $)^{10}$.

Las causas apuntadas para el desvío de la declaración con relación a la verdad objetiva eran de diversas índoles e incluían las condiciones psicológicas del proprio testigo, su envolvimiento emocional con el tema del crimen, la influencia del ambiente, la impregnación de la subjetividad del redactor de la declaración en su relato, o del propio interrogador («hay formas de inquirir que son verdaderas sugerencias de la respuesta deseada»). Las declaraciones de las mujeres, por ejemplo, eran consideradas menos confiables, debido a la mayor sugestionabilidad que caracterizaría al sexo femenino (Rodrigues, 1922, p. 109). Katzenstein, además, resaltaba la importancia de la edad, de la inteligencia y del tipo biológico del declarante como factores que deben ser considerados al apreciar la veracidad de sus palabras (Katzenstein, 1940, p. 211).

Por último, la ciencia tenía que «medir», por medio de exámenes periciales, la credibilidad del testimonio y, al cuestionarlo y relativizarlo, acababa fortaleciendo la autoridad del propio examen pericial del delincuente.

\section{CONCLUSIÓN}

Se cerraba el "cerco al circo». Desde la perspectiva de la Escuela Positiva, la precariedad de los procesos judiciales se iniciaba en los interrogatorios policiales, productores de pruebas falsas por incuria o truculencia y se consagraba en las salas de los tribunales, donde los jurados las aceptaban sin salvedades, al igual que las declaraciones de los testigos. Solo los hombres de ciencia, con los médicos a la cabeza, podrían romper ese círculo vicioso, interponiéndose en varios puntos críticos del proceso, controlando y disciplinando los procedimientos y calificando los resultados.

En este enredo de disputas por la autoridad sobre el cuerpo humano, las tesis biodeterministas lograron significativa influencia social, siempre movilizadas por las pericias médico legales y disciplinadas por saberes científicos. Pero el balance del alcance de su programa, bastante extensivo a causa del optimismo epistemológico que los determinismos suelen propiciar, es necesariamente parcial. No solo existía la referida disputa paradigmática en el interior del conjunto de 
las especialidades médicas, que perseguía la primacía en la construcción de la etiología del acto antisocial, sino también la necesidad de afirmación sobre otras tradiciones culturales extra científicas de producción de verdad, como analizamos anteriormente. El estudioso del asunto no tiene otra opción a no ser evitar las generalizaciones y las simplificaciones esquemáticas, tan seductoras como estériles. Por último, los es-

\section{NOTAS}

1 Traducción libre. Todas las demás citas también fueron libremente traducidas del portugués.

2 Sobre el papel decisivo del médico bahiano Nina Rodrigues en la búsqueda del reconocimiento de las prerrogativas profesionales del médico legista en Brasil, véase Corrêa, 1998.

3 Sobre el tema, véase Ferla, 2009, pp. 161-206.

4 Sobre las relaciones entre poder y producción de verdad, Foucault dice: "No hay ejercicio del poder sin una cierta economía de los discursos de verdad que funcionan en ese poder, a partir y a través de él. Somos sometidos por el poder a la producción de la verdad y solo podemos ejercer el poder mediante la producción de la verdad» (Foucault, 2000, p. 28-29).

5 La bastardilla es nuestra. pacios institucionales de combate al desvío comportamental, desde las represión policial hasta las cortes jurídicas, pasando por establecimientos de internación suministran material rico para el estudio tanto del alcance de los determinismos biológicos en un período durante el cual circulaban intensamente, como de la afirmación social de la ciencia y de las estrategias que utilizaba para lograrlo.

\section{BIBLIOGRAFÍA}

Alvarez, Marcos (1996), Bacharéis, criminologistas e juristas: saber jurídico e nova escola penal no Brasil (1889-1930). Tese de doutoramento, Faculdade de Filosofia, Letras e Ciências Humanas, Universidade de São Paulo.

Antunes, José Leopoldo Ferreira (1999), Medicina, Leis e Moral: pensamento médico e comportamento no Brasil (1870-1930). São Paulo, Unesp.

Ássaly, Alfredo Issa (1943), "Atestados de antecedentes criminais. Considerações legais e sociais", Arquivos da Polícia Civil de São Paulo, São Paulo, 5, pp. 511-514.

Cancelli, Elizabeth (2001), A cultura do crime e da lei (1889-1930). Brasília, EdUnB.

Chauí, Marilena (1982), Cultura e democracia: o discurso competente e outras falas. São Paulo, Moderna.

Corrêa, Mariza (1998), As Ilusões da Liberdade: a Escola Nina Rodrigues e a Antropologia no Brasil. Bragança Paulista, EdUSF.

Darmon, Pierre (1991), Médicos e assassinos na "Belle Époque": a medicalização do crime. Rio de Janeiro, Paz e Terra.

Fausto, Boris (1984), Crime e cotidiano: a criminalidade em São Paulo (1880-1924). São Paulo, Brasiliense.

6 En 1891, 2932 casos se enviaron al tribunal del jurado, mientras que 200 mil sentencias se dictaron en los tribunales correccionales (Harris, 1993, p. 151)

7 La bastardilla es nuestra.

8 Ver, por ejemplo, los pareceres 694 (Lehmann, 1947) y 1050 (Ferreira, 1947).

9 Sobre Binet y su escala para la medición del $\mathrm{Cl}$, véase Gould, 1999, pp. 149-162.

10 Katzenstein había trabajado en el Instituto de Psicología de Hamburgo, bajo la dirección de William Stern, uno de los principales estudiosos de la psicología del testimonio (Katzenstein, 1940, p. 200). Su presencia en Brasil en 1940 se debía muy probablemente a su condición de refugiada del nazismo.

Fávero, Flamínio; Lehmann, Otto Cyrillo; Duarte, Aureliano R.; Silva, Boaventura N.; Almeida Júnior, Antônio de; Morais, Flávio Q. (1947), “Conselho", Revista Penal e Penitenciária, São Paulo, 4-8 (1-2), pp. 169-70.

Fávero, Flamínio (1947), "Conselho Penitenciário do Estado", Revista Penal e Penitenciária, São Paulo, 4-8 (1-2), pp. 273-276.

Fávero, Flamínio (1936), "Relatório do Secretário Geral", Archivos da Sociedade de Medicina Legal e Criminologia de S. Paulo, 3 (2), pp. 149-153.

Ferla, Luis (2009), Feios, sujos e malvados sob medida: a utopia médica do biodeterminismo. São Paulo, Alameda/FAPESP.

Ferreira, Siqueira (Rel.) (1947), "Conselho - Parecer n 1050", Revista Penal e Penitenciária, São Paulo, 4-8 (1-2), pp. 218-221.

Foucault, Michel (1999), Vigiar e punir. História da Violência nas Prisões. Petrópolis, Vozes.

Foucault, Michel (2000), Em defesa da sociedade. São Paulo, Martins Fontes.

Foucault, Michel (2001), Os anormais. São Paulo, Martins Fontes.

Goffman, Erving (1974), Manicômios, Prisões e Conventos. São Paulo, Perspectiva. 
Gould, S. J. (1999), A Falsa Medida do Homem. São Paulo, Martins Fontes.

Harris, Ruth (1993), Assassinato e loucura: medicina, leis e sociedade no fin de siècle. Rio de Janeiro, Rocco.

Katzenstein, Betti (1940), "A Psychologia da testemunha”, Archivos da Sociedade de Medicina Legal e Criminologia de S. Paulo, 11 (1-3), pp. 199-219.

Lehmann, Otto C. (1947), "Conselho - Parecer n 694”, Revista Penal e Penitenciária, São Paulo, 4-8 (1-2), pp. 182-189.

Lombroso, César (2001), O homem delinqüente. Porto Alegre, Ricardo Lenz.

Machado, Alcântara (1929), "A psychologia do testemunho - de um curso de medicina pública para estudantes de direito", Revista de Criminologia e Medicina Legal, São Paulo, 4 (1-2), pp. 47-78.

Mello, José de Moraes (1928), “O pensamento medico-legal hodierno em face da projectada reforma do codigo penal brasileiro", Revista de Criminologia e Medicina Legal, São Paulo, 1, pp.15-39.

Pereira, Virgílio de Sá (1929), “Da imputabilidade no projecto de Codigo Panal brasileiro", Revista de Criminologia e Medicina Legal, São Paulo, 6, pp. 7-12.
Peres, Maria Fernanda P (2002), “A doença mental no direito penal brasileiro: inimputabilidade, irresponsabilidade, periculosidade e medida de segurança", História, Ciências, Saúde: Manguinhos, 9 (2), pp. 335-355.

Peset, Jose Luis; Peset, Mariano (1975), Lombroso y la Escuela Positivista italiana. Madrid, CSIC.

Queiroz Filho, Antônio de (1947), "Informação do Diretor Geral", Revista Penal e Penitenciária, São Paulo, 4-8 (1-2), pp. 168-169.

Rodrigues, Armando (1922), "Psychologia da prova testemunhal", Archivos da Sociedade de Medicina Legal e Criminologia de S. Paulo, 1 (3-4), pp. 107-118.

Salgado, Cesar (1932), "Novos rumos da criminologia", Archivos da Sociedade de Medicina Legal e Criminologia de São Paulo, 3 (3), pp. 53-70.

Salla, Fernando (1999), As prisões em São Paulo: 1822 a 1940. São Paulo, Annablume.

Teles, João Carlos da Silva (1947), “Conclusões Gerais”, Revista Penal e Penitenciária, 4-8 (1-2), pp. 163-168.

Whitaker, Edmur de A (1943), "O caso do Viaduto do Chá - um autoacusador - estudo criminológico", Arquivos da Polícia Civil de São Paulo, 5, pp. 295-342. 